\title{
Study of Rheological Properties of Doughs for Pasta with Cassava Bran Addition and Supplemented with Hydrocolloid
}

\author{
Andrea C. Acosta ${ }^{1 *}$, Elvis J. Hernández ${ }^{1}$ and Armando Alvis ${ }^{2}$ \\ 'Department of Agro-industrial Engineering, University of Sucre, Sincelejo - 70001, Colombia; \\ andreina9110@hotmail.com, elvis.hernandez@unisucre.edu.co \\ ${ }^{2}$ School of Engineering, Department of Food Engineering, University of Cordoba, Monteria, Colombia; \\ aalvis@correo.unicordoba.edu.co
}

\begin{abstract}
Objective: The objective of this research study was to evaluate cassava bran and xanthan gum effect on rheological properties of doughs for fiber rich pasta. Methods/Analysis: Pastas with 10, 20 and 30\% bran additions and xanthan gum in 0.5, 1 and $1.5 \%$ concentrations were prepared. Rheological characterization of doughs was carried out through dynamic oscillatory tests with frequency and time sweeps. Also, a sensory evaluation of cooked pasta was carried out evaluating firmness, elasticity, color, taste and overall impression, through a hedonic test of product acceptance. Findings: In viscoelastic characterization, elastic modulus prevailed over the viscous one and increase in amounts of bran and gum caused an increasing trend in the modules. Sensory acceptance decreased with bran increase in the pasta; however, gum addition improved its evaluation. Novelty: This work showed that a product rich in fiber and with good sensory acceptance can be obtained with use of an agroindustrial waste such as cassava bran and able to strengthen the cassava productive chain nationwide.
\end{abstract}

Keywords: Fiber and Hydrocolloid, Sensory Attributes Rheological Behavior

\section{Introduction}

Industrial use of cassava is done through starch production. During the process, solid and liquid waste are generated, within which, bran is generated in the greatest quantity (1507 kg bran on a wet basis are generated for each ton of processed cassava). Cassava bran has $85 \%$ humidity that makes it difficult to store and transport, turning it into a focus of environmental contamination if not managed properly. However, due to its high fiber content, it can be used to be reincorporated into the production cycle 1 , being able to generate added value to food products. Foods rich in dietary fiber can contribute to prevention of important disorders of the large intestine, such as constipation, diverticulitis and colon cancer². Addition of dietary fiber in foods can be made through total or partial replacement of one of its constituents with another one rich in fiber that can improve its nutritional value. Studies have been reported aimed at incorporating fiber in foods such as breads, pasta, beverages and cereals, among others $s^{3-5}$.

Pasta is considered a healthy food relatively low in fat, high in carbohydrates and protein. In recent years, various ingredients have been used in pasta production to improve nutritional profile or confer functional properties; however, amount of raw material that can be used as

*Author for correspondence 
a substitute for wheat semolina represents a compromise between nutritional improvement and satisfaction of sensory properties of pasta ${ }^{6}$.

Generally, rheological properties of pastas depend on protein amount and gluten viscoelasticity. To replace gluten and improve final product quality, various materials have been used; hydrocolloids ${ }^{\underline{z}}$, among these, thanks to their water binding capacity that helps control dough rheology ${ }^{8}$. Dough rheological study helps to understand effects of non-traditional ingredients on its flow properties during extrusion?.

The objective of this study was to study rheological behavior of dough for fiber-rich pasta with partial substitution of wheat semolina by cassava bran and supplemented with xanthan gum (GX), to obtain a product with greater nutritional value and good sensory acceptance

\section{Methodology}

\subsection{Raw Material and Conditioning}

Bran used was obtained from cassava starch production variety $M$-Thai, supplied by Almidones de Sucre S.A.S company from the city of Sincelejo-Colombia. Wheat semolina and XG were supplied by Harinera Pardo S.A company and Bell Chem International S.A company respectively.

Cassava bran was conditioned by pressing at 10PSI and then drying in a tray dryer at $55^{\circ} \mathrm{C}$ air temperature for 24 hours until reaching a $11 \mathrm{~g} / 100 \mathrm{~g}$ final humidity. Finally, it was subject to a grinding and sieving process up to completely pass through a 40 mesh $^{10}$.

\subsection{Process of Making Pasta}

For pasta preparation, the cassava bran and wheat semolina were mixed with $1 \%$ (flour base) salt for $5 \mathrm{~min}$. XG was dissolved in water with a paddle stirrer until an even distribution $^{11}$. Then, mixing and kneading ingredients were carried out for 10 minutes in a pasta extruder machine. A Fettucine type pasta with a $4 \mathrm{~mm}$ diameter was the result. Finally, they were dried at $70^{\circ} \mathrm{C}$ in a conventional oven until a final humidity between 10 and $11.5 \%$.

\subsection{Statistical Analysis}

A $3 \times 3$ factorial experimental design was carried out with a substitution of wheat semolina for 10, 20 and 30\% cassava bran and adding Xanthan Gum (XG) at 0.5, 1 and $1.5 \%$ concentrations respectively, for a total of nine treatments. Data were analyzed by means of the statistical package R 3.2.1 free version. An Analysis Of Variance (ANOVA) was performed $(\mathrm{p} \leq 0.05)$ and Tukey test was used to compare means. Tests were carried out in triplicate and the mean was estimated with its respective standard deviation.

\subsection{Rheological Properties of Doughs}

Rheological study of doughs was carried out by dynamic oscillatory tests to the dough by using a Modular Rheometer MCR 302, connected to the Anton Paar RheoCompass 1.12 software. Geometry of parallel plates with a $25 \mathrm{~mm}$ diameter placed at $1 \mathrm{~mm}$ among them was used. The sample was loaded in the rheometer and a 15 min rest period was given. Measurements were made in the Linear Viscoelastic Region (LVR), determined by sweeping amplitude in a deformation range between 0.01 $100 \%$ and $1.0 \mathrm{~Hz}$ frequency. Viscoelastic characterization was performed by varying the frequency $(0.01-10 \mathrm{~Hz})$ to determine storage modulus ( $G$ ') (elastic property) and loss modulus (G") (viscous property). They were fitted to a power law model (Eq. 1 and 2) where $K^{\prime}, K^{\prime \prime}, n^{\prime}, n^{\prime \prime}$ are constants and $\omega$ is the angular frequency. Later delta tangent, $\tan (\delta)$ was determined (Eq. 3). Also, a time sweep at $1.0 \mathrm{~Hz}$ was performed for $30 \mathrm{~min}$ to define stability of viscoelastic properties of doughs at low deformation rates ${ }^{11}$.

$$
\begin{aligned}
& G^{\prime}=K^{\prime}(\omega)^{n^{\prime}} \\
& G^{n}=K^{\prime \prime}(\omega)^{n^{n g}} \\
& \operatorname{Tan}(\delta)=\frac{\mathrm{G}^{n}}{\mathrm{G}^{\prime}}
\end{aligned}
$$




\subsection{Sensory Evaluation}

A sensory evaluation of pasta formulations made by an acceptance test was carried out using a 9-point mixed structured hedonic scale (1- I extremely dislike it, 9- I extremely like it) (Mirhosseini et al., 2015), evaluating attributes such as: Texture (firmness and elasticity), color, taste and product overall impression, evaluated by a 50-habitual consumer panel of pasta tasters. The product was randomly located and was coded with a three-digit number. The most widely accepted pasta was sensory valued with a traditional commercial fettuccine type pasta.

All treatments were cooked until reaching the "pasta al dente" state, that is, total cooking up to the pasta interior and then to cooling with immersion in water at $25^{\circ}$ C. They were subject to heat conditions by circulating air for $10 \mathrm{~min}$ before being served to the tasters without adding additives $\underline{12,13}$.

\subsection{Physico-chemical Characterization}

Humidity content, ashes, proteins, total carbohydrates, total fiber (soluble and insoluble) and fat were determined to the elaborated pasta that obtained greater sensorial acceptance according to the AOAC official norms. (2012).

\section{Results and Discussion}

\subsection{Rheological Properties of Doughs}

Viscoelastic behavior of doughs as a function of frequency is shown in Figure 1. The storage modulus (G') of the different treatments was greater than the loss modulus ( $G$ "). Indeed, elastic properties predominated compared to viscose ones, thus, doughs can be defined as a consistent elastic gel ${ }^{14}$. This behavior occurs in highly

Table 1. Rheological parameters K' y K' 'of the Power Law model of cassava bran pasta and supplemented with XG

\begin{tabular}{|c|c|c|c|}
\hline \multirow{2}{*}{ GX (\%) } & \multicolumn{3}{|c|}{ Amount of bran (\%) } \\
\cline { 2 - 4 } & 10 & 20 & 30 \\
\hline 0,5 & $54832,84 \pm 6051,21^{\mathrm{cB}}$ & $166914,7 \pm 2886,57^{\mathrm{bA}}$ & $168597,48 \pm 19530,27^{\mathrm{bA}}$ \\
\hline 1 & $111503,85 \pm 10649,09^{\mathrm{aC}}$ & $163587,12 \pm 5916,61^{\mathrm{bB}}$ & $187771,52 \pm 3747,42^{\mathrm{abA}}$ \\
\hline 1,5 & $87573,27 \pm 2879,98^{\mathrm{bB}}$ & $210104,47 \pm 21679,1^{\mathrm{aA}}$ & $205842,62 \pm 5430,73^{\mathrm{aA}}$ \\
\hline & & & $K^{\prime \prime}$ \\
\hline 1 & $48854,74 \pm 2846,32^{\mathrm{aB}}$ & $68896,61 \pm 3826,83^{\mathrm{bA}}$ & $76215,09 \pm 7165,65^{\mathrm{abA}}$ \\
\hline 1,5 & $40482,57 \pm 2097,27^{\mathrm{abB}}$ & $97411,34 \pm 10794,67^{\mathrm{aA}}$ & $85532,72 \pm 2771,5^{\mathrm{aA}}$ \\
\hline
\end{tabular}

Means with different letters in columns (lowercase) and rows (uppercase) indicate a statistically significant difference according to Turkey test $(\mathrm{p}<0.05)$ 


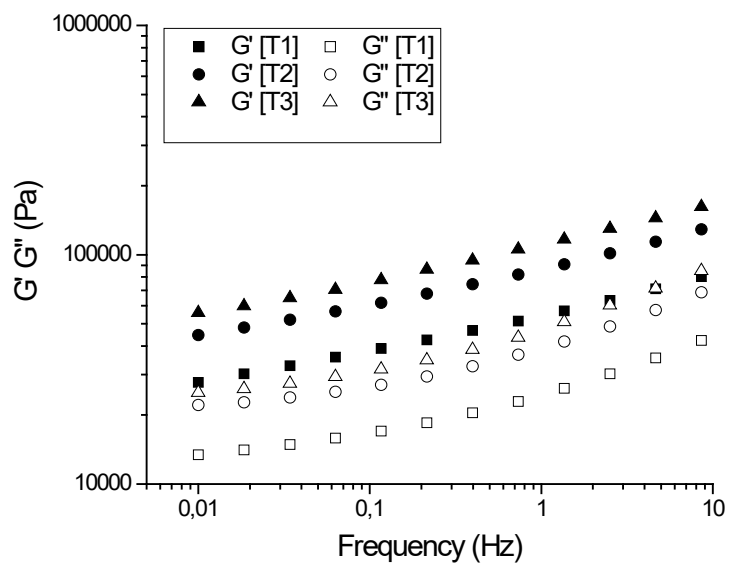

(a)

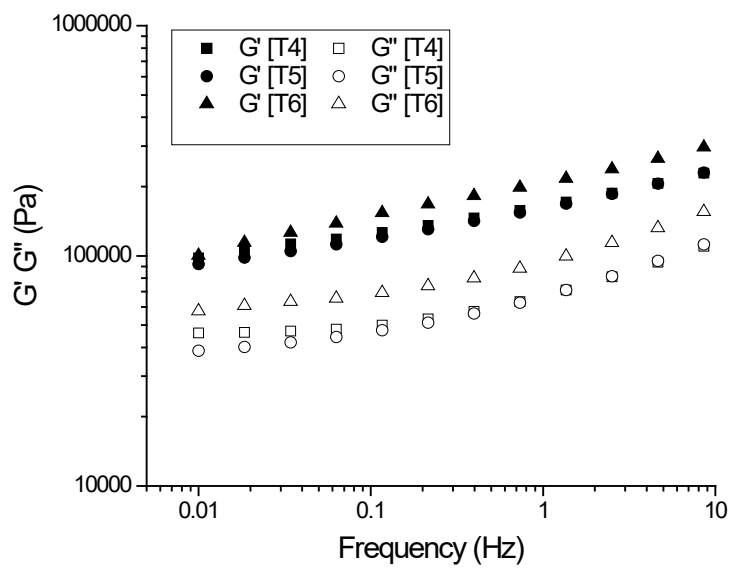

(b)

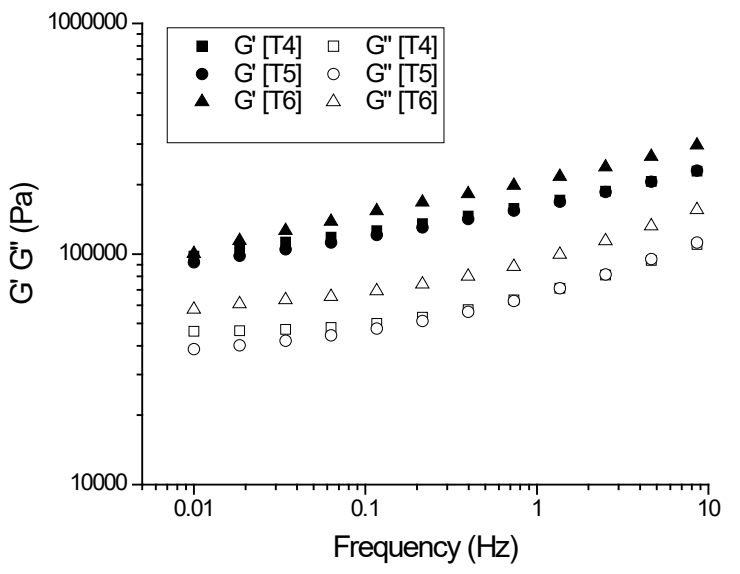

(c)

Figure 1. Viscoelastic dough behavior as a function of frequency for cassava bran pasta in (a) $10 \%$, (b) $20 \%$ and (c) $30 \%$ additions and supplemented with xanthan gum $(\mathrm{GX})$ in: $(\boldsymbol{\square}, \square) 0.5 \%,(\boldsymbol{\bullet}, 0) 1 \%$ and $(\boldsymbol{\Delta}, \Delta) 1.5 \%$ concentrations (Black symbols (G'); White symbols (G”).

structured materials ${ }^{\underline{8}}$, typical of products with gluten presence, allowing networks creation in the matrix and optimal formation of the mixture ${ }^{15}$. Comparable results were observed in pasta made with $\operatorname{corn}^{\frac{8}{}}$, wheat flour $\frac{16}{}$, and rice ${ }^{\frac{17}{7}}$, where values of $\mathrm{G}^{\prime} 5$ to 10 times greater than those of G" were found, and as the frequency increased, the G" module decreased, showing a system that acted more elastically ${ }^{11}$. Furthermore, an increase was observed in both modules with the angular frequency, similar behavior was observed in chestnut flour doughs added with hydrocolloids $\frac{18}{}$.

An increasing trend was also observed in the value of modules with the increase in amount of added bran, showing a greater viscoelastic character, possibly due to a stronger structure as indicated by the increase in viscoelastic constants ${ }^{18}$. This behavior may be associated to the use of raw materials rich in fiber, generating more solid doughs due to effect of fiber on the waterabsorption ${ }^{19}$. 
Table 2. Rheological parameters n' 'and Tan $(\delta)$ of the Power Law model of cassava bran pasta and supplemented with XG

\begin{tabular}{|c|c|c|c|}
\hline \multirow{2}{*}{ GX (\%) } & \multicolumn{3}{|c|}{ Amount of bran (\%) } \\
\cline { 2 - 4 } & $\mathbf{1 0}$ & $\mathbf{2 0}$ & 30 \\
\hline 0,5 & $0,179 \pm 0,00^{\mathrm{aA}}$ & $\mathbf{n}^{\prime}$ & $0,135 \pm 0,01^{\mathrm{aB}}$ \\
\hline 1 & $0,175 \pm 0,00^{\mathrm{aA}}$ & $0,148 \pm 0,00^{\mathrm{aB}}$ & $0,145 \pm 0,00^{\mathrm{aB}}$ \\
\hline 1,5 & $0,182 \pm 0,01^{\mathrm{aA}}$ & $0,159 \pm 0,00^{\mathrm{aAB}}$ & $0,138 \pm 0,01^{\mathrm{aC}}$ \\
\hline 0,5 & & $0,161 \pm 0,00^{\mathrm{aB}}$ & $0,397 \pm 0,01^{\mathrm{aB}}$ \\
\hline 1 & $0,437 \pm 0,00^{\mathrm{aA}}$ & $\operatorname{Tan}(\delta)$ & $0,381 \pm 0,03^{\mathrm{aB}}$ \\
\hline 1,5 & $0,446 \pm 0,03^{\mathrm{aA}}$ & $0,397 \pm 0,00^{\mathrm{bB}}$ & $0,401 \pm 0,00^{\mathrm{aB}}$ \\
\hline
\end{tabular}

Means with different letters in columns (lowercase) and rows (uppercase) indicate a statistically significant difference according to Turkey test $(\mathrm{p}<0.05)$

Correspondingly, increase in XG concentration increased the value of modules. This is possibly associated with the ability of hydrocolloids to mimic viscoelastic properties of gluten present in the semolina ${ }^{20}$, so that increasing the percentage of these compounds in the dough produces a stronger material. A similar behavior was reported in flour doughs from hydrothermally treated glutinous rice added with XG, indicating the formation of stronger gels, thanks to the thickening effect of GX in fluids ${ }^{1 \frac{18}{}}$. Likewise, an increase in the elastic modulus in gluten doughs was reported with the increase in the amount of Arabic gum and pectin $\frac{16}{}$.

The viscoelastic estimated parameters for the power law model ( $\left.K^{\prime}, n^{\prime} y K^{\prime \prime}\right)$ of cassava bran and XG pasta had significant differences $(\mathrm{p} \leq 0.05)$, except for parameter $\mathrm{n}$ ", as shown in Tables 1,2 . It is observed that increasing bran amount in doughs results in the highest values of $\mathrm{K}$ ' $\mathrm{y}$ K” in any of the concentrations evaluated for XG. Comparable results were found in doughs from chestnut flour supplemented with XG in 0.5 to $2 \%^{\frac{17}{17}}$ concentrations.

Increase in XG concentration produced an increase in consistency coefficients $K$ 'and $K$ ' ', coinciding with the increase in the values of both modules, probably associated with a better interaction between components of doughs thanks to the stabilizing and thickener action of the gums. Results found by ${ }^{16}$ suggest that hydrocolloids are interfering with gluten bonds formation, affecting the elastic and viscous modules to a different extent; considering that glutenins, a gluten protein fraction, have been associated with elastic behavior and gliadins that confer viscosity. These proteins allow a good network connection of the matrix and the formation of an optimal dough ${ }^{21}$. A similar behavior was reported by ${ }^{17,8}$ in gluten-free doughs added with Hydrocolloid.

Considering that values of n' $y$ n" obtained were low, but different from zero, it is possible to define rheological behavior of doughs as weak gels. Although interaction 
of study factors was not significant for n", each factor was significant, and its values are different from zero. Comparable results were reported by ${ }^{22}$ for gluten-free doughs prepared from rice and added with dietary fibers. On the other hand, no significant differences were found when increasing the XG amount for each dough made with different amounts of bran. Comparable results were observed in gluten-free doughs based on rice, showing that the addition of b-glucan had no significant effect 22 .

Figure 2 shows the behavior of the Tan $(\delta)$ of the doughs made with cassava bran and XG. This parameter allows to relate the viscous module (G") with the elastic modulus (G'), evaluated according to frequency. Since, the G" module was greater than the G" module, values of Tan $(\delta)$ were less than 1 , confirming the behavior as a viscoelastic gel of the formulated doughs, given by the proteins present in the semolina and joined together by disulfide bridges, hydrogen and hydrophobic bonds to form a matrix ${ }^{23}$. Comparable results were found in doughs for gluten-free pastas based on rice ${ }^{22}$. Lower values of Tan $(\delta)$ indicate a material behavior with predominance of the elastic component over the viscous one. Furthermore, it was found that this parameter is dependent on frequency,

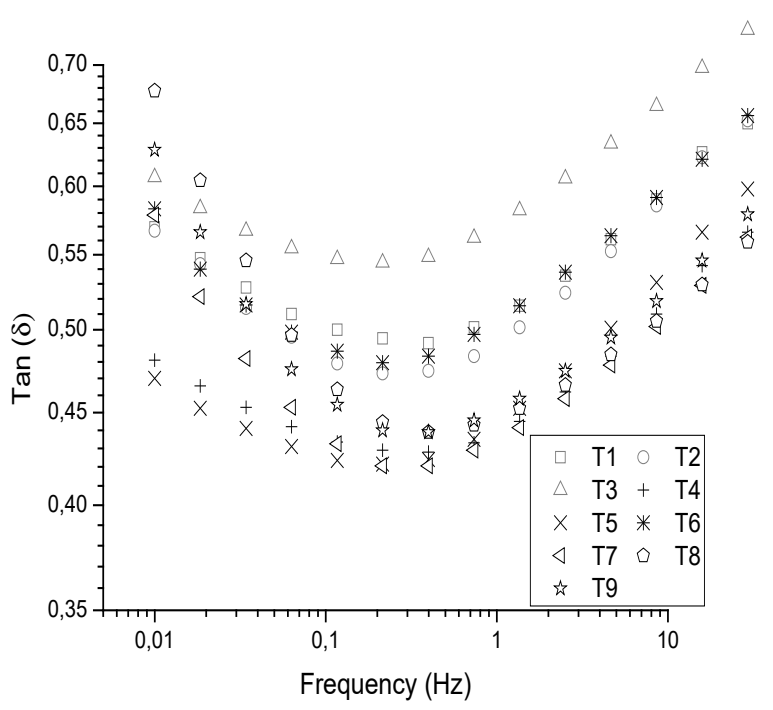

Figure 2. Behavior of Tan $(\delta)$ of doughs with 10,20 and $30 \%$ cassava bran and xanthan gum (XG) in $0.5,1$ and $1.5 \%$ concentrations. detailing a $\tan (\delta)$ general trend to decrease at low frequencies $(<1.0 \mathrm{~Hz})$, and then increase as oscillation speeds increase $(>1.0 \mathrm{~Hz})$.

Regarding loss tangent, significant differences were reported $(\mathrm{p} \leq 0.05)$ and values obtained were less than 1 . $\operatorname{Tan}(\delta)$ value tends to decrease as the amount of bran added to doughs increases with XG in any of the concentrations evaluated. It was found that doughs prepared with greater bran content showed the highest values in the modules, indicating more rigid structures and affected by the addition of fiber present in the bran. This causes loss of integrity of the gluten network and affects its structure ${ }^{24}$ point out that replacing wheat flour with fibrous materials has a significant effect on rheological behavior of doughs.

On the other hand, it was observed that Tan $(\delta)$ showed the highest values when using XG at $1.5 \%$ concentration, indicating that the greater amount of added gum, the increase in gel strength is favored, possibly since gums improve the relation among the starch granules $\frac{18}{}$. Typical of GX solutions is the increase in elastic properties and predominance of the elastic modulus that gives it the weak gel characteristic ${ }^{10}$. Research conducted by ${ }^{17}$ point out that type and quantity of hydrocolloid added to doughs have a major influence on tangent values, which is associated to the molecular structure and polysaccharide chain conformation that determine intermolecular physical associations of the polymer chains.

Behavior of the elastic and viscous modules as a function of time is shown in Figure 3, which helps to show the stability of viscoelastic properties of doughs. In all cases, the elastic modulus predominates over the viscose one, reiterating the elastic forces of doughs. Furthermore, it can be observed that modules of doughs with greater amount of bran are more affected by time.

Increase in $\mathrm{XG}$ concentration in doughs caused an increase in its rigidity throughout the measurement, which can be observed by the high and constant G' values. Comparable results were observed in plasticized resins of zein and kafirin, causing increase in firmness over time ${ }^{25}$. However, results observed by ${ }^{26-27}$ in zein starch dough supplemented with hydroxypropylmethylcellulose (HPMC) and oat bran with b-glucan show a decrease in 


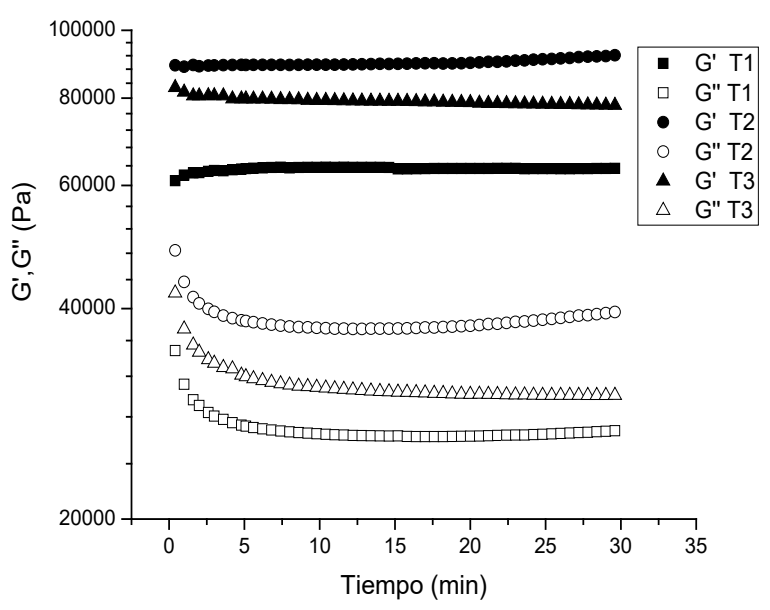

(a)

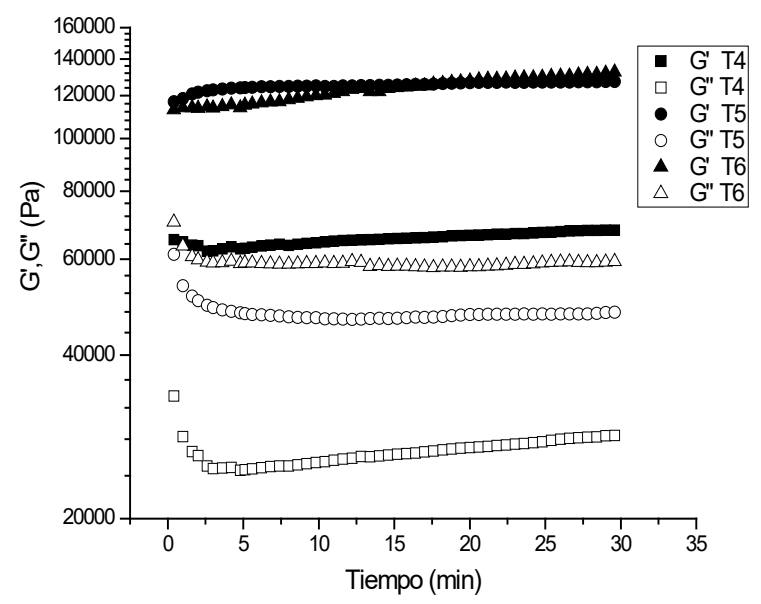

(b)

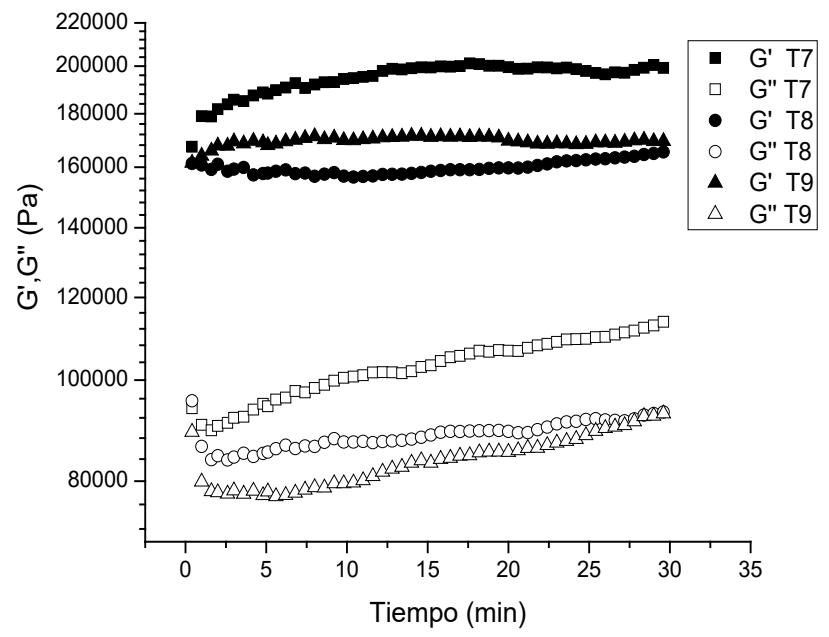

(c)

Figure 3. Viscoelastic dough behavior as a function of time for cassava bran pasta in (a) $10 \%$, (b) $20 \%$ and (c) $30 \%$ additions and supplemented with xanthan gum $(\mathrm{GX})$ in $(\boldsymbol{\square}, \mathbf{\square}) 0.5 \%,(\bullet, \circ) 1 \%$ and $(\boldsymbol{\Lambda}, \Delta) 1.5 \%$ concentrations. (Black symbols $\left(\mathrm{G}^{\prime}\right)$; White symbols $\left(G^{\prime \prime}\right)$ ).

firmness by adding these hydrocolloids with respect to the control without hydrocolloids.

\subsection{Sensory Evaluation}

Acceptance level of pasta made with cassava bran and supplemented with XG was evaluated by fifty habitual tasters of pasta, considering attributes such as texture (firmness and elasticity), color, taste and overall product impression, showing significant statistical differences $(\mathrm{p} \leq 0.05)$ for all evaluated attributes. Table 3 shows results obtained, highlighting the pasta formulated with $10 \%$ bran and $0.5 \%$ XG in terms of attributes of firmness, elasticity, taste and product overall impression. Pastas formulated with $20 \%$ bran and $1.5 \%$ XG in attributes of 
Table 3. Average results of the acceptance test of pastas made with XG

\begin{tabular}{|c|c|c|c|c|c|c|}
\hline $\begin{array}{c}\text { Amount of bran } \\
(\%)\end{array}$ & Amount of GX (\%) & Firmness & Elasticity & Color & Flavor & $\begin{array}{c}\text { General } \\
\text { Sensation }\end{array}$ \\
\hline \multirow{2}{*}{10} & 0,5 & $6,02^{\mathrm{a}}$ & $5,60^{\mathrm{a}}$ & $5,28^{\mathrm{bc}}$ & $5,30^{\mathrm{a}}$ & $5,88^{\mathrm{ab}}$ \\
\cline { 2 - 7 } & 1 & $5,40^{\mathrm{abc}}$ & $5,18^{\mathrm{abc}}$ & $4,58^{\mathrm{cd}}$ & $4,90^{\mathrm{ab}}$ & $5,32^{\mathrm{bcd}}$ \\
\hline \multirow{3}{*}{20} & 1,5 & $4,60^{\mathrm{c}}$ & $5,42^{\mathrm{ab}}$ & $6,58^{\mathrm{a}}$ & $5,06^{\mathrm{a}}$ & $5,86^{\mathrm{ab}}$ \\
\cline { 2 - 7 } & 0,5 & $5,06^{\mathrm{bc}}$ & $4,82^{\mathrm{abc}}$ & $5,28^{\mathrm{bc}}$ & $5,30^{\mathrm{a}}$ & $4,46^{\mathrm{e}}$ \\
\cline { 2 - 7 } & 1 & $5,34^{\mathrm{abc}}$ & $4,98^{\mathrm{abc}}$ & $5,50^{\mathrm{b}}$ & $5,30^{\mathrm{a}}$ & $6,30^{\mathrm{a}}$ \\
\hline \multirow{2}{*}{30} & 1,5 & $5,44^{\mathrm{abc}}$ & $5,16^{\mathrm{abc}}$ & $6,70^{\mathrm{a}}$ & $5,28^{\mathrm{a}}$ & $6,36^{\mathrm{a}}$ \\
\cline { 2 - 7 } & 1 & $5,02^{\mathrm{bc}}$ & $4,52^{\mathrm{c}}$ & $4,02^{\mathrm{de}}$ & $3,82^{\mathrm{c}}$ & $4,82^{\mathrm{cde}}$ \\
\hline & 1,5 & $5,30^{\mathrm{abc}}$ & $4,64^{\mathrm{bc}}$ & $4,06^{\mathrm{de}}$ & $4,10^{\mathrm{bc}}$ & $5,38^{\mathrm{bc}}$ \\
\hline & $5,50^{\mathrm{ab}}$ & $4,88^{\mathrm{abc}}$ & $3,44^{\mathrm{e}}$ & $4,92^{\mathrm{ab}}$ & $4,50^{\mathrm{de}}$ \\
\hline
\end{tabular}

Means with different letters in columns indicate a statistically significant difference $(p \leq 0.05)$

color, flavor and overall impression were also outstanding and obtained good results in the textural parameters of firmness and elasticity.

As for the sensory attributes of firmness and elasticity perceived by tasters, these were found among the hedonic terms "I slightly dislike it " and "I slightly like it ". As for the elasticity, pastas made with $30 \%$ bran showed a lower valuation compared to the others. This can be associated with the greater amount of bran that affects this property.

Regarding color, it was found that tasters valued pasta between the hedonic terms "I mildly dislike it" and "I like it moderately", highlighting that pastas made with $30 \%$ bran presented the least consumer acceptance, given their darker coloration due to the greater addition of bran in its formulation, causing a change in the tonality of pastas. Comparable results were found in the sensorial evaluation of pasta with inclusion of soybean meal and channa ${ }^{\mathrm{T}}$.

On the other hand, the taste attribute evaluated by the tasters was found between the hedonic terms "I slightly dislike " and "Indifferent". Regarding the overall impression of the product, the tasters placed it between the hedonic terms "Indifferent" and "I like it slightly". This attribute is possibly affected by the presence of fiber fragments in the pasta as the quantity of added bran increases, so that the pasta with $30 \%$ bran obtained a lower value. Differently, studies conducted by ${ }^{13}$ report that the global impression of pasta is favored by the increase in the amount of gums such as Xanthan and carob.

Considering the results obtained in the acceptance of pasta, the pasta made with $20 \%$ bran and $1.5 \%$ XG was selected for its subsequent sensory evaluation with a commercial one. Results are shown in Table 4. The commercial pasta showed the greatest acceptance in the parameters evaluated by the consumers, being found in the hedonic term "I slightly like it ". However, consumers did not perceive statistical differences $(p \geq 0.05)$ among samples in terms of their color despite addition of bran in the formulation, which results in darker pastas; nonetheless, in 
Table 4. Average results of the acceptance test of the selected pasta and a commercial one

\begin{tabular}{|c|c|c|c|c|c|}
\hline Pasta & Firmness & Elasticity & Color & Flavor & $\begin{array}{c}\text { General } \\
\text { Sensation }\end{array}$ \\
\hline $\begin{array}{c}20 \% \text { Bran y } \\
1,5 \% \text { GX }\end{array}$ & $5,38^{\mathrm{b}}$ & $5,06^{\mathrm{b}}$ & $5,56^{\mathrm{a}}$ & $4,12^{\mathrm{b}}$ & $5,10^{\mathrm{b}}$ \\
\hline Commercial & $6,30^{\mathrm{a}}$ & $6,28^{\mathrm{a}}$ & $6,18^{\mathrm{a}}$ & $5,98^{\mathrm{a}}$ & $6,22^{\mathrm{a}}$ \\
\hline
\end{tabular}

Means with different letters in columns indicate a statistically significant difference $(\mathrm{p} \leq 0.05)$

those made with $30 \%$ bran, this trend is highlighted even more.

In terms of firmness and overall impression, comparable results were reported by ${ }^{3}$ in pastas with addition of carob bean fiber, where the higher the inclusion of fiber, the lower the valuation for these attributes, receiving the highest of control pasta acceptance. Low elasticity and firmness of the processed pasta with respect to the commercial one can be associated to the interruption of fiber with the formation of gluten network in the pasta mass 28 , especially affecting the evaluated texture attributes.

Regarding the color attribute, this was negatively affected by the inclusion of bran in the formulation of the pasta. Comparable results were reported in pasta with bran addition ${ }^{3}$.

\subsection{Physicochemical Characterization of the Best Food Pasta}

The physicochemical characteristics of the best pasta. Fiber content found shows the increase in this nutrient thanks to the addition of cassava bran in the formulation with respect to the fiber found in pasta made from $100 \%$ wheat semolina ( $0.42 \%$ fiber). Similar observations were found in pasta made from pregelatinized maize flour, corn flour and yellow pepper flour, where it was observed that fiber content was higher than the control (100\% corn flour), which they attributed to the higher content of this nutrient in vegetables with respect to cereals $s^{21}$; nevertheless, their values in terms of total, soluble and insoluble fiber are lower than those reported in the present study $\underline{12}$ found an increase in protein and fiber content in pastas with addition legume meal. Specifically, an increase in fiber content in a range from $77 \%$ to $275 \%$ was observed compared to wheat pasta ( $0.92 \%$ total fiber). Alternatively, results found differ from those reported for gluten-free pasta with amaranth, with the fiber being less (5.49\%), but the protein at a higher level (12.8\%), these differences are related to nutritional composition of amaranth rich in protein and lower in fiber compared to cassava bran ${ }^{28}$.

Considering the standards established by the European Commission 2006 for foods with fiber, pasta made with partial substitution of wheat semolina by cassava bran and supplemented with XG, it could be considered close to a "Fiber source" food. However, it should be noted that pasta was made only with the ingredients mentioned and addition of others such as egg, oil and dehydrated vegetables could further improve their nutritional characteristics, which are a function of the proximal composition of the ingredients used.

\section{Conclusions}

Viscoelastic behavior of dough showed that elastic properties prevailed over the viscous ones, therefore, values of Tan $(\delta)$ were less than 1 and doughs can be defined as an elastic gel. Increase in amount of bran caused an increase in modules and the increase in the amount of added gums allowed to obtain a stronger and more elastic dough. Sensory acceptance test revealed that tasters found significant differences in the evaluated attributes, finding the highest acceptance in the pasta made with $20 \%$ cassava bran and $1.5 \%$ XG. 
On the other hand, the acceptance of the commercial pulp was higher compared to the pulp elaborated in all the attributes evaluated, except for the color that did not show significant differences. Physicochemical characterization of the best pasta showed that addition of cassava bran in its formulation favored fiber content.

\section{References}

1. Farias F, Jasko A, Colman T, Pinheiro L, Schnitzler E, Barana A. Y Demiate I. Characterisation of cassava bagasse and composites prepared by blending with lowdensity polyethylene. Brazilian Archives of Biology and Technology. 2014; 57(6):821-30. https://doi.org/10.1590/ S1516-8913201402506.

2. Foschia M, Peressini D, Sensidoni A, Y Brenan C. The effects of dietary fibre addition on the quality of common cereal Products. Journal of Cereal Science. 2013; 58(2):21627. https://doi.org/10.1016/j.jcs.2013.05.010.

3. Biernacka B, Dziki D, Gawlik-Dziki U, Różyło R, Siastała M. Physical, sensorial, and antioxidant properties of common wheat pasta enriched with carob fiber. LWT-Food Science and Technology. 2017; 77:186-92. https://doi. org/10.1016/j.lwt.2016.11.042.

4. Lorusso A, Verni M, Montemurro M, Coda R, Gobbetti M, Rizzello CG. Use of fermented quinoa flour for pasta making and evaluation of the technological and nutritional features. LWT-Food Science and Technology. 2017; 78:215-21. https://doi.org/10.1016/j.lwt.2016.12.046.

5. Verdú S, Barat JM, Y Grau R. Improving bread-making processing phases of fibre-rich formulas using chia (Salvia hispanica) seed flour. LWT-Food Science and Technology. 2017; 84:419-25. https://doi.org/10.1016/j.lwt.2017.06.007.

6. Gull A, Prasad K, Y Kumar P. Effect of millet flours and carrot pomace on cooking qualities, color and texture of developed pasta. LWT-Food Science and Technology. 2015; 63(1):470-4. https://doi.org/10.1016/j.lwt.2015.03.008.

7. Susanna S, Y Prabhasankar P. A study on development of Gluten free pasta and its biochemical and immunological validation. LWT-Food Science and Technology. 2013; 50:613-21. https://doi.org/10.1016/j.lwt.2012.07.040.

8. Larrosa V, Lorenz G, Zaritzky N, Y Califano, A. Optimization of rheological properties of gluten-free pasta dough using mixture design. Journal of Cereal Science. 2013; 57(3):5206. https://doi.org/10.1016/j.jcs.2013.03.003.

9. De la Pe-a E, Manthey F, Patel B, Y Campanella O. Rheological properties of pasta dough during pasta extrusion: Effect of moisture and dough formulation. Journal of Cereal Science. 2014; 60:346-51. https://doi.org/10.1016/j.jcs.2014.05.013.
10. Fiorda F, Soares M, Da Silva F, De Moura C, Y Grosmann M. Physical quality of snacks and technological properties of pre-gelatinized flours formulated with cassava starch and dehydrated cassava bagasse as a function of extrusion variables. LWT-Food Science and Technology. 2015; 62(2):1112-19. https://doi.org/10.1016/j.lwt.2015.02.030.

11. Sozer N. Rheological properties of rice pasta dough supplemented with proteins and gums. Food Hydrocolloids. 2009; 23:849-55. https://doi.org/10.1016/j.foodhyd.2008.03.016.

12. Wojtowicz A, Y Moscicki L. Influence of legume type and addition level on quality characteristics, texture and microstructure of enriched precooked pasta. LWT-Food Science and Technology. 2014; 59:1175-85. https://doi. org/10.1016/j.lwt.2014.06.010.

13. Mirhosseini H, Rashid N, Amid B, Cheong K, Kazemi M, Y Zulkurnain M. Effect of partial replacement of corn flour with durian seed flour and pumpkin flour on cooking yield, texture properties, and sensory attributes of gluten free pasta. LWT-Food Science and Technology. 2015; 63(1):184-90. https://doi.org/10.1016/j.lwt.2015.03.078.

14. Li J, Y Nie S. The functional and nutritional aspects of hydrocolloids in foods. Food Hydrocolloids. 2016; 53:4661. https://doi.org/10.1016/j.foodhyd.2015.01.035.

15. Feillet P, Y Dexter J. Quality requirements of durum wheat for semolina milling and pasta production. Pasta and Noodle Technology; 1996. p. 95-131.

16. Bárcenas M, De la O-Keller J, Y Rosell C. Influence of different hydrocolloids on major wheat dough components (gluten and starch). Journal of Food Engineering. 2009; 94(3):2417. https://doi.org/10.1016/j.jfoodeng.2009.03.012.

17. Moreira R, Chenlo F, Y Torres M. Rheology of commercial chestnut flour doughs incorporated with gelling agents. Food Hydrocolloids. 2011; 25(5):1361-71. https://doi. org/10.1016/j.foodhyd.2010.12.015.

18. Cai J, Chiang J, Tan M, Saw L, Xu Y, Y Ngan-Loong M. Physicochemical properties of hydrothermally treated glutinous rice flour and xanthan gum mixture and its application in gluten-free noodles. Journal of Food Engineering. 2016; 186:1-9. https://doi.org/10.1016/j.jfoodeng.2016.03.033.

19. Guadarrama A, Carrillo H, Pérez C, Vernon E, Y Alvarez J. Thermal and rheological properties of sponge cake batters and texture and microstructural characteristics of sponge cake made with native corn starch in partial or total replacement of wheat flour. LWT-Food Science and Technology. 2016; 70:46-54. https://doi.org/10.1016/j.lwt.2016.02.031.

20. Lazaridou A, Duta D, Papageorgiou M, Belc N, Y Biliaderis C. Effects of hydrocolloids on dough rheology and bread quality parameters in gluten-free formulations. Journal of Food Engineering. 2007; 79(3):1033-47. https://doi. org/10.1016/j.jfoodeng.2006.03.032. 
21. Padalino L, Mastromatteo M, Lecce L, Cozzolino F, Y Del Nobile MA. Manufacture and characterization of gluten-free spaghetti enriched with vegetable flour. Journal of Cereal Science. 2013; 57(3):333-42. https://doi. org/10.1016/j.jcs.2012.12.010.

22. Ronda F, Pérez S, Angioloni A, Y Collar C. Impact of viscous dietary fibres on the viscoelastic behaviour of gluten-free formulated rice doughs: a fundamental and empirical rheological approach. Food Hydrocolloids. 2013; 32(2):252-62. https://doi.org/10.1016/j.foodhyd.2013.01.014.

23. Foschia M, Peressini DO, Sensidoni A, Brennan A, Y Brennan C. How combinations of dietary fibres can affect physicochemical characteristics of pasta. LWT-Food Science and Technology. 2015; 61(1):41-6. https://doi. org/10.1016/j.lwt.2014.11.010.

24. Rubel I, Pérez E, Manrique G, Y Genovese D. Fibre enrichment of wheat bread with Jerusalem artichoke inulin: Effect on Dough Rheology and Bread Quality. Food Structure. 2015; 3:21-9. https://doi.org/10.1016/j.foostr.2014.11.001.

25. Oom A, Pettersson A, Taylor JRN, Y Stading M. Rheological properties of Kafirin and Zein Prolamins. Journal of
Cereal Science. 2008; 47:109-16. https://doi.org/10.1016/j. jcs.2007.02.005.

26. Andersson H, Öhgren C, Johansson D, Kniola M, Y Stading M. Extensional flow, viscoelasticity and baking performance of gluten-free zein-starch doughs supplemented with hydrocolloids. Food Hydrocolloids. 2011; 25:1587-95. https://doi.org/10.1016/j.foodhyd.2010.11.028.

27. La Gatta B, Rutigliano M, Padalino L, Conte A, Del Nobile MA, Y Di Luccia A. The role of hydration on the cooking quality of bran-enriched pasta. LWT-Food Science and Technology. 2017; 84:489-96. https://doi.org/10.1016/j. lwt.2017.06.013.

28. Cabrera F, De la Barca A, Islas A, Marti A, Marengo M, Pagani M, Bonomi F, Y Lametti S. Molecular rearrangements in extrusion processes for the production of amaranth-enriched, gluten-free rice pasta. LWT-Food Science and Technology. 2012; 47(2):421-6. https://doi. org/10.1016/j.lwt.2012.01.040. 